\title{
EFEITOS DO CONDICIONAMENTO FISIOLÓGICO E DA SECAGEM NA GERMINAÇÃO E NO VIGOR DE SEMENTES DE CENOURA ${ }^{1}$
}

\author{
ERNANDOBALBINOT ${ }^{2}$, HIGINOMARCOSLOPES $^{3}$
}

\begin{abstract}
RESUMO - O condicionamento fisiológico de sementes foi avaliado sob diferentes metodologias, incluindo a imersão de sementes em soluções aeradas, seguidas ou não de secagem. O objetivo deste trabalho foi avaliar os efeitos do condicionamento osmótico em sistema aerado seguido de secagem sobre a germinação e o vigor de sementes de cenoura, cultivar Brasília. Utilizaram-se sementes submersas em 40mL de água destilada e em soluções de PEG-6000, nas concentrações de 161,30 e $240,97 \mathrm{~g} . \mathrm{L}^{-1}$ a $15^{\circ} \mathrm{C}$, correspondentes aos potenciais hídricos de $-0,4 \mathrm{e}-0,8 \mathrm{MPa}$, durante os períodos de 12, $24 \mathrm{e} 48$ horas. As sementes após o condicionamento, foram submetidas à secagem em estufa com circulação de ar, a $35^{\circ} \mathrm{C}$, por 1, 2, 3, 4, e 5 horas, determinando-se o teor de água das sementes. Os efeitos do condicionamento e da secagem foram avaliados por meio do teste de germinação, primeira contagem do teste de germinação, classificação do vigor de plântulas, comprimento e massa seca de plântulas e condutividade elétrica. O teor de água das sementes diminuiu linearmente com o tempo de secagem. O condicionamento das sementes seguido de secagem não afetou a germinação e contribuiu para aumentar o vigor das sementes em relação às sementes sem condicionamento.
\end{abstract}

Termos para indexação: Daucus carota L., priming, teor de água.

\section{EFFECTS OF OSMOCONDITIONING AND DRYING ONCARROT SEED GERMINATION ANDVIGOR}

\begin{abstract}
Seed priming was evaluated under different technologies including the immersion of seeds in solutions with oxygen supply, followed or not by drying processes. The objectives of this study were to evaluate the effects of osmotic conditioning on systems with oxygen supply followed by drying on the germination and the vigor in carrot seeds, cv. "Brasilia". The seeds were submerged in 40mL distilled water and PEG 6000 solutions at 161,30 and $240,97 \mathrm{~g} . \mathrm{L}^{-1}$ corresponding, respectively, to the osmotic potentials of $-0,4$ and $-0,8 \mathrm{MPa}$, at $15^{\circ} \mathrm{C}$, with oxygen supply, during 12,24 and 48 hours. The seeds were dried in an oven at $35^{\circ} \mathrm{C}$, with air circulation for $1,2,3,4$, and 5 hours and seed moisture content was determined. The effects of the osmotic conditioning and drying were evaluated by the germination test, first count of the germination test, seedling vigor classification, seedling length and mass and electrical conductivity. The seed moisture content decreased linearly with the time when submitted to the drying process. Osmoconditioning followed by seed drying did not affect the germination and contributed to increasing the seed vigor in relation to non osmoconditioned seeds.
\end{abstract}

Index terms: Daucus carota L., priming, seed moisture content.

\section{INTRODUÇÃO}

Os tratamentos de pré-germinação de sementes reduzem o tempo entre a semeadura e a emergência das plântulas, bem

\footnotetext{
${ }^{1}$ Submetido em 12/07/2004. Aceito para publicação em 06/06/2005. Apoio FAPERJ - RJ;

${ }^{2}$ Estudante de pós-graduação - UENF; ernando@uenf.br;

${ }^{3}$ Professor Adjunto IV-Dr. Departamento de Fitotecnia - UFRRJ; Higino@ufrrj.br.
}

como aumenta a tolerância das sementes às condições adversas do ambiente. Dentre as técnicas que têm sido estudadas para esta finalidade, destaca-se o condicionamento osmótico, que consiste na hidratação controlada das sementes até um determinado nível, permitindo a ocorrência das etapas iniciais do processo de germinação, sem, contudo, ocorrer a protrusão da raiz primária (Heydecker, 1975; Bradford, 1986).

Embora esta técnica envolva custos, tanto operacional 
como de pesquisa, a utilização de sementes condicionadas ainda pode ser considerada compensadora, pois o tempo decorrido entre a semeadura e a colheita pode ser reduzido, possibilitando retorno financeiro em menor tempo, principalmente para a atividade de produção de mudas de hortaliças ou culturas em que se utiliza a semeadura direta (Nascimento, 1998).

$\mathrm{O}$ aumento do vigor de sementes condicionadas tem sido obtido por meio de diferentes métodos e combinações entre potenciais hídricos, temperaturas e períodos de condicionamento com sementes de alface (Santos e Menezes, 2000), cebola (Trigo et al., 1999a, b, c; Lopes et al., 2000; Nunes et al., 2000) e cenoura (Pelúzio et al., 1999).

Powell (1998) relata que o condicionamento por meio da hidratação controlada das sementes, sob aeração, durante 36 horas a $20^{\circ} \mathrm{C}$ pode atenuar o envelhecimento de sementes de couve-flor. Segundo Trigo et al. (1999b, c), o condicionamento osmótico pode reverter o processo de envelhecimento natural de sementes de cebola, pois quando estas foram osmocondicionadas, mantiveram sua viabilidade por até seis meses de armazenamento.

As diferentes técnicas de hidratação das sementes podem influenciar a resposta ao condicionamento. Em algumas espécies, como feijão, a imersão completa das sementes por 8 horas, reduziu 55 pontos percentuais na germinação e diminuiu o vigor, causando prejuízos irreversíveis às sementes (Custódio et al., 2002). Por outro lado, sementes de feijão hidratadas por 24 horas até $15,6 \%$ de umidade, utilizando o método adaptado do teste de envelhecimento acelerado, e submetidas à secagem até 9,3\%, germinaram mais rápido em relação aquelas sem hidratação (Aragão et al., 1999).

A secagem das sementes após o condicionamento é desejável, pois facilita seu manuseio e armazenamento, evitando expor as sementes ao risco de danos mecânicos provocados pelos equipamentos de semeadura.

$\mathrm{O}$ efeito do condicionamento de sementes de alface por períodos de até seis dias a $20^{\circ} \mathrm{C}$ e em presença de luz e posteriormente submetidas à secagem a $32^{\circ} \mathrm{C}$, por 12 horas, em estufa com circulação de ar, variou em função da cultivar e do período de condicionamento osmótico (Fessel et al., 2002).

Santos e Menezes (2000) submeteram sementes de alface osmocondicionadas em soluções de polietileno glicol à secagem a $32^{\circ} \mathrm{C}$, até atingir $13 \%$ de umidade e observaram efeitos negativos da secagem sobre a porcentagem de germinação e diminuição no comprimento de plântulas em todos os períodos testados. Sementes de cebola, após o condicionamento, foram secas em estufa de ar forçado a $30^{\circ} \mathrm{C}$, até o retorno à umidade inicial não apresentando redução da germinação (Trigo et al., 1999a). Neste caso, o processo de germinação estava nos estágios iniciais, devido à restrição a absorção de água e a secagem não afetou o processo.

Os objetivos deste trabalho foram avaliar o efeito do condicionamento osmótico e da secagem das sementes de cenoura cv. Brasília sobre a germinação e o vigor.

\section{MATERIAL E MÉTODOS}

Este trabalho foi realizado no Laboratório de Controle de Qualidade de Sementes do Departamento de Fitotecnia da Universidade Federal Rural do Rio de Janeiro. Foram utilizadas sementes de cenoura (Daucus carota L.), cultivar Brasília, com $89 \%$ de germinação, 99\% de pureza e $8,7 \%$ de umidade. As sementes foram previamente classificadas por tamanho, retidas em peneira de crivo redondo com $1,41 \mathrm{~mm}$ de diâmetro e, posteriormente mantidas em embalagem impermeável e armazenadas a $10^{\circ} \mathrm{C}$.

O método utilizado para o condicionamento osmótico das sementes consistiu no uso de tubos de ensaio, sobre suporte de madeira, com suprimento de ar externo através de bombas de diafragma, adaptado de Lopes et al. (2000). Utilizou-se dois gramas de sementes, submersas em $40 \mathrm{~mL}$ de água destilada e soluções de PEG 6000, nas concentrações de 161,30 e $240,97 \mathrm{~g} . \mathrm{L}^{-1}$, correspondendo aos potenciais osmóticos de $-0,4$ e $-0,8 \mathrm{MPa}$, respectivamente (Michel e Kaufmann, 1973). O condicionamento foi realizado a $15^{\circ} \mathrm{C}$, com 8 horas diárias de luz, durante os períodos de 12, 24 e 48 horas de condicionamento. Após cada período, as sementes foram retiradas, lavadas em água corrente durante um minuto para a remoção dos resíduos das soluções e secas sobre papel toalha por 15 minutos, em condições de temperatura e umidade relativa do ambiente. Foi determinado o teor de água das sementes de acordo com o aumento de peso destas, relacionando com o peso e a umidade inicial. Paralelamente, quatro amostras de sementes de cada tratamento foram pesadas e submetidas à secagem em estufa com circulação de ar a $35^{\circ} \mathrm{C}$ por $1,2,3,4$, e 5 horas. Após cada período, as sementes foram retiradas, resfriadas em dessecador e pesadas, obtendo-se o teor de água por diferença entre o peso inicial e final. Considerando-se a umidade inicial, obteve-se a relação entre o tempo de secagem em horas e o teor de água em porcentagem, ou "curva de secagem". Após a secagem até a umidade inicial, as sementes foram armazenadas em embalagem impermeável e mantidas a $10^{\circ} \mathrm{C}$ por 20 dias. Para 
a avaliação da qualidade fisiológica das sementes condicionadas e secas e o controle sem tratamento, utilizaram-se os seguintes testes:

Teste de germinação: realizado com quatro repetições de 50 sementes semeadas sobre três folhas de papel germitest, umedecidas com água destilada na proporção de três vezes o peso do substrato, no interior de caixas tipo gerbox, envolvidas em sacos de polietileno, com o objetivo de evitar a perda de água para o meio. As sementes permaneceram em câmaras de germinação reguladas a $20-30^{\circ} \mathrm{C}$ e a avaliação foi realizada aos 14 dias, registrando-se a porcentagem de plântulas normais (Brasil, 1992). Primeira contagem do teste de germinação: constou do registro da porcentagem de plântulas normais, ocorrido no sétimo dia após a implantação do teste de germinação (Brasil, 1992). Classificação do vigor de plântulas: após sete dias do inicio do teste de germinação, efetuou-se o registro das plântulas sem a presença de qualquer deficiência ou irregularidade em suas estruturas essenciais, que permitiriam classificá-las como normais. Foi considerado um padrão, de acordo com o comprimento da plântula e o diâmetro do hipocótilo, acima do qual as plântulas foram classificadas como normais fortes e abaixo como normais fracas, segundo Nakagawa (1999). Comprimento de plântulas: realizado com quatro repetições de 20 sementes, sobre três folhas de papel germitest, umedecidas com água destilada na proporção de três vezes o seu peso, no interior de caixas plásticas tipo gerbox, envolvidas em sacos de polietileno, condicionadas em câmaras de germinação à temperatura de $20-30^{\circ} \mathrm{C}$. As sementes foram orientadas em uma única posição, dispostas sobre duas linhas traçadas a dois terços da parte inferior do substrato, e as caixas foram dispostas inclinadas, formando um ângulo de $45^{\circ}$ em relação a horizontal. A avaliação foi realizada aos sete dias após o início do teste, medindo-se o comprimento das plântulas normais e obtendo-se o valor médio, expresso em centímetros (Nakagawa, 1999). Massa seca de plântula: realizada juntamente com o teste de comprimento de plântulas, consistiu da secagem das plântulas em estufa a $70^{\circ} \mathrm{C}$ por 24 horas e posterior pesagem, adaptado de Nakagawa (1999). Condutividade elétrica: Efetuada com quatro repetições de 50 sementes para cada tratamento, que foram pesadas e imersas em $75 \mathrm{~mL}$ de água destilada e mantidas por 24 horas à temperatura de $25^{\circ} \mathrm{C}$. A avaliação foi realizada com o auxílio de um condutivímetro. Os resultados foram expressos em $\mu \mathrm{S} . \mathrm{cm}^{-1} \cdot \mathrm{g}^{-1}$ de sementes (Vieira e Krzyzanowski,1999). Avaliou-se a condutividade elétrica da solução remanescente após cada tratamento de condicionamento e os resultados expressos em $\mu \mathrm{S} . \mathrm{cm}^{-1} \cdot \mathrm{g}^{-1}$.

$\mathrm{O}$ delineamento experimental utilizado foi o inteiramente casualizado, com quatro repetições, num esquema fatorial 3x4, envolvendo três concentrações de PEG 6000: 0,0 (água destilada), 161,30 e 240,97g. $\mathrm{L}^{-1}$, em quatro períodos de condicionamento: zero, 12, 24 e 48 horas. Os resultados obtidos foram submetidos à análise de variância e de regressão. As médias foram comparadas entre si pelo teste de Tukey a 5\% de probabilidade.

\section{RESULTADOS E DISCUSSÃO}

Na Tabela 1, destaca-se o aumento significativo do teor de água nas sementes nas primeiras 12 horas de embebição. Em água destilada, o teor de água obtido nas sementes não se alterou com o período de embebição até 48 horas, sugerindo que com 12 horas de embebição estas se encontravam em estado de equilíbrio de absorção de água ou fase II da embebição (Bewley e Black, 1994). Entretanto, nas soluções de PEG, o teor de água de equilíbrio foi alcançado com 24 horas, evidenciando a redução da taxa de absorção de água causada pelo PEG. O teor de água obtido em sementes condicionadas em água destilada após 12 horas foi superior àquele obtido em sementes condicionadas em solução de 240g. $\mathrm{L}^{-1}$ de PEG. Estes resultados evidenciam o menor volume de água absorvido pelas sementes em solução osmótica, mesmo quando estas estão completamente imersas, como observado por Lopes et al. (2000) e Trigo et al. (1999 b, c). Após 24 horas esta diferença não foi significativa, indicando um período de equilíbrio na absorção de água. Entretanto, após 48 horas, a diferença no teor de água entre os tratamentos com água e $240 \mathrm{~g} . \mathrm{L}^{-1}$ de $\mathrm{PEG}$ foi novamente observada.

Lopes et al. (2000) condicionaram sementes de cenoura, cultivar Brasília, entre papel e em soluções aeradas com PEG 6000 a $15^{\circ} \mathrm{C}$, concluindo que a imersão das sementes em soluções aeradas promove uma absorção mais rápida em relação daquelas entre papel, porém os dois métodos foram eficientes em melhorar a germinação e o vigor. $\mathrm{O}$ estado

TABELA 1. Teor de água (\%) em sementes de cenoura, cv. Brasília, após o condicionamento em água e em soluções de PEG 6000 por 12, 24 e 48 horas a $15^{\circ} \mathrm{C}$ $(\mathrm{CV}=4,2 \%)$

\begin{tabular}{llll}
\hline & 12 horas & 24 horas & 48 horas \\
\hline AGUA & $50,9 \mathrm{Aa}$ & $52,2 \mathrm{Aa}$ & $53,0 \mathrm{Aa}$ \\
PEG 161,3 gL & $44,2 \mathrm{Bab}$ & $49,3 \mathrm{Aa}$ & $47,6 \mathrm{ABab}$ \\
PEG 240,0 gL & $42,8 \mathrm{Bb}$ & $48,0 \mathrm{Aa}$ & $46,0 \mathrm{ABb}$ \\
\hline
\end{tabular}

Médias seguidas de mesma letra maiúscula na linha e minúscula na coluna, não diferem entre si pelo teste de Tukey $(\mathrm{P}<0,05)$. 
energético da água nas sementes é responsável pelo controle da embebição e germinação. Na retomada do crescimento embrionário, o teor de água da semente difere acentuadamente entre espécies e pode variar entre cultivares, embora, os potencias hídricos do embrião apresentam-se em níveis semelhantes (Egli e Tekrony, 1997; Villela et al., 2003).

O teor de água das sementes, no processo de secagem, decresceu seguindo uma resposta linear em função do tempo em todos os tratamentos (Figuras 1, 2 e 3). As sementes condicionadas em água, 161,03 e 240,97g.L. - $^{-1}$ de PEG 6000, após 5 horas de secagem, atingiram 14, 10,87 e 10,31\%, respectivamente (Figura 1). As sementes quando foram condicionadas em água atingiram, em media, 52,06\% de umidade, superior àquelas condicionadas em PEG e, em conseqüência, foi observado maior teor de água, após o mesmo período de secagem.

O teor de água, na base úmida, estimado ao final do condicionamento e após a secagem foi baseado, respectivamente, no aumento e redução do peso das sementes com $8,7 \%$ de teor de água inicial. Entretanto, evidências demonstraram que houve lixiviação de solutos durante o processo de condicionamento, e consequentemente perda de massa seca das sementes, resultando em teores de água superiores, após a secagem por 5 horas, ao teor de água inicial de $8,7 \%$. Nestas condições, para que as sementes retornem ao seu teor de água inicial, deve-se aumentar o tempo de secagem. Em trabalhos envolvendo condicionamento de sementes, os valores de teor de água calculado por diferenças de peso, podem estar superestimados.

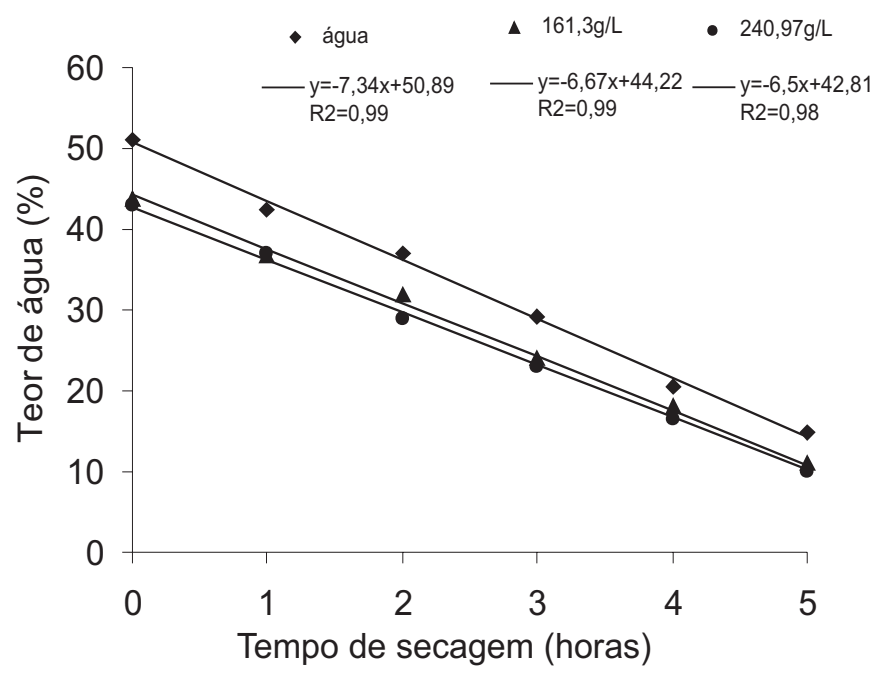

FIGURA 1. Estimativa da curva de secagem (horas), para sementes de cenoura após o condicionamento osmótico por 12 horas em função dos tratamentos de embebição em soluções aeradas.

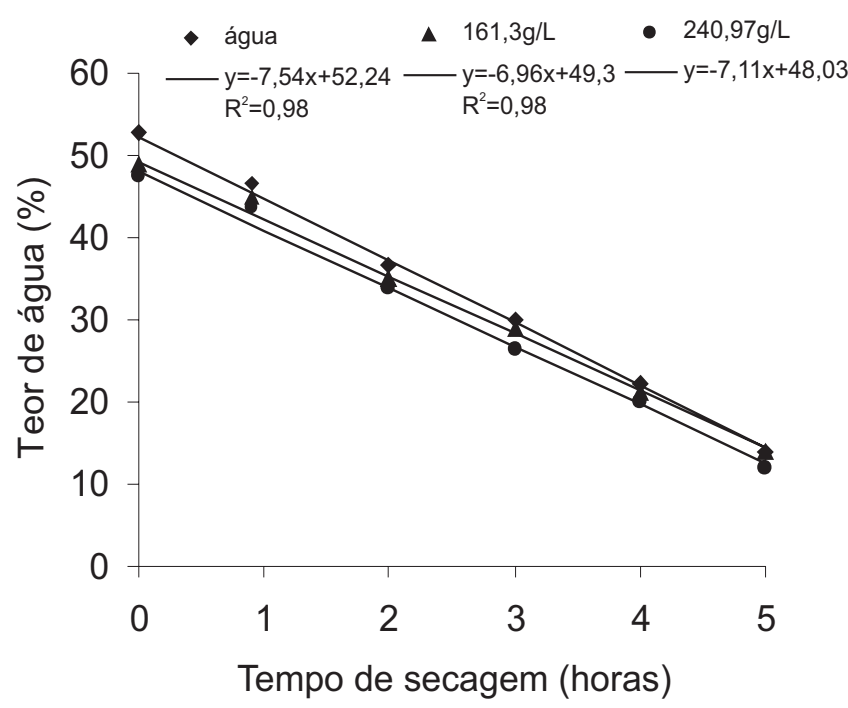

FIGURA 2. Estimativa da curva de secagem (horas) para sementes de cenoura após o condicionamento osmótico por 24 horas em função dos tratamentos de embebição em soluções aeradas.

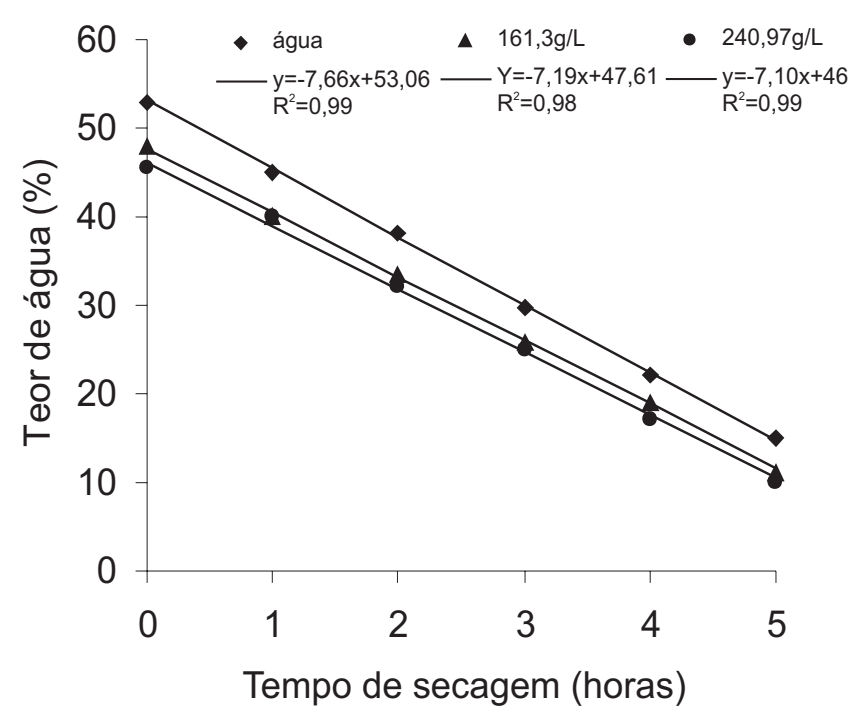

FIGURA3. Estimativa da curva de secagem (horas) para sementes de cenoura após o condicionamento osmótico por 48 horas em função dos tratamentos de embebição em soluções aeradas.

As sementes de cenoura depois de condicionadas em água atingiram, em média, $52,1 \%$ de umidade e secaram a taxa de $7,5 \%$ por hora e, quando foram condicionadas em PEG atingiram, em media, $46,3 \%$ de umidade e secaram a taxa de 7,1\% por hora (Figuras 1, 2 e 3). A menor taxa de secagem observada em sementes condicionadas com PEG pode ser atribuída à permanência de resíduos de solução de PEG nas sementes mesmo após a lavagem destas. 
A germinação de sementes de cenoura variou entre 77,5 e $91 \%$ e não apresentou diferenças significativas entre os períodos de condicionamento (Tabela 2). Foi observada diferença na germinação entre o condicionamento em água e a concentração de $161,3 \mathrm{~g} \cdot \mathrm{L}^{-1}$ de PEG por 24 horas. Estes resultados assemelham-se àqueles encontrados por Trigo et al. (1999b), em sementes de cebola condicionadas em soluções aeradas de nitrato de potássio, concordando que as condições ideais do teste de germinação e sua metodologia de avaliação não permitem que os benefícios do condicionamento osmótico sejam evidenciados.

O teste de germinação não é uma boa ferramenta para avaliar diferenças de tratamentos de sementes de um mesmo lote e que apresentam elevada qualidade fisiológica, como também observado por Carvalho et al. (2000), que verificaram efeito favorável na germinação de sementes de sorgo somente utilizando sementes com qualidade fisiológica inferior, e por Roveri-José et al. (2000), que observaram diferenças na porcentagem de germinação apenas quando o teste foi conduzido em estresse térmico. Além disso, o desempenho germinativo pode apresentar grande variação em função de espécies, cultivares de uma mesma espécie e lotes de um mesmo cultivar, como confirmou Carneiro et al. (1999), que observaram aumento no percentual germinativo de sementes de cenoura condicionadas do cultivar TimTom.

Os efeitos do condicionamento e secagem foram evidenciados sobre o vigor das sementes, representado pela primeira contagem do teste de germinação (Tabela 3). Houve incremento na porcentagem de plântulas normais em relação à testemunha para todos os tratamentos. Os resultados deste teste demonstram que o condicionamento osmótico de sementes de cenoura, nos tratamentos utilizados aumentou a velocidade de germinação corroborando com os resultados obtidos por Biniek e Babik (1993); McDonald (1998) e Pelúzio et al. (1999).

TABELA 2. Médias de germinação (\%) de sementes de cenoura, cv. Brasília, condicionadas em soluções aeradas de PEG 6000 e em água destilada, por períodos de zero (testemunha), 12, 24 e 48 horas de embebição e submetidas à secagem $(\mathrm{CV}=4,98 \%)$

\begin{tabular}{clcc}
\hline \multirow{2}{*}{ Período (horas) } & Água destilada & \multicolumn{2}{c}{$\left[\right.$ PEG 6000] $\left(\mathrm{g.L} \mathrm{L}^{-1}\right)$} \\
\cline { 3 - 4 } & & 161,30 & 240,97 \\
\hline Zero & $85,5 \mathrm{Aa}$ & $85,5 \mathrm{Aa}$ & $85,5 \mathrm{Aa}$ \\
24 & $83,5 \mathrm{Aa}$ & $77,5 \mathrm{Aa}$ & $81,5 \mathrm{Aa}$ \\
48 & $91,0 \mathrm{Aa}$ & $82,5 \mathrm{Ba}$ & $86,5 \mathrm{Aba}$ \\
\hline
\end{tabular}

Médias seguidas de mesma letra maiúscula na linha e minúscula na coluna, não diferem entre si pelo teste de Tukey $(\mathrm{P}<0,05)$.
Todos os tratamentos aumentaram a porcentagem de plântulas fortes em relação à testemunha (Tabela 4), porém, para o tratamento com PEG na maior concentração, nos períodos de 12 e 48 horas, a diferença não foi significativa. Este resultado permite inferir que a utilização de soluções com potenciais mais negativos, ou maior concentração de PEG (240,97g. $\left.\mathrm{L}^{-1}\right)$ e períodos de condicionamento maior (48 horas) podem prejudicar o desenvolvimento das plântulas, conforme relatado por Nunes et al. (2000).

Houve diferenças na porcentagem de plântulas fracas dentro de cada período de condicionamento, porém, os tratamentos de um modo geral não diferiram da testemunha. Comparando os percentuais de plântulas fracas (Tabela 5) com os de plântulas fortes (Tabela 4), verifica-se uma relação entre os resultados obtidos para cada tratamento, uma vez que o total de plântulas fortes e fracas fornece a porcentagem de germinação final. Entretanto, a avaliação de classificação do vigor de plântulas evidenciou com maior segurança, em relação ao teste de germinação, a comparação entre tratamentos.

O condicionamento de sementes de cenoura por 48 horas em água resultou em maior comprimento de plântulas em

TABELA3. Médias de plântulas normais (\%) obtidas na primeira contagem do teste de germinação de sementes de cenoura condicionadas em soluções aeradas de PEG 6000 e água destilada, por períodos de zero (testemunha), 12, 24 e 48 horas de embebição e submetidas à secagem $(\mathrm{CV}=9,31 \%)$

\begin{tabular}{clcc}
\hline \multirow{2}{*}{ Período (horas) } & \multirow{2}{*}{ Água destilada } & \multicolumn{2}{c}{$\left[\right.$ PEG 6000] $\left(\mathrm{g} \cdot \mathrm{L}^{-1}\right)$} \\
\cline { 3 - 4 } & & 161,30 & 240,97 \\
\hline zero & $55,0 \mathrm{Ab}$ & $55,0 \mathrm{Ab}$ & $55,0 \mathrm{Ab}$ \\
12 & $73,0 \mathrm{Aa}$ & $68,5 \mathrm{Aab}$ & $73,0 \mathrm{Aa}$ \\
24 & $86,0 \mathrm{Aa}$ & $74,5 \mathrm{Aa}$ & $79,0 \mathrm{Aa}$ \\
48 & $81,0 \mathrm{Aa}$ & $78,0 \mathrm{Aa}$ & $82,5 \mathrm{Aa}$ \\
\hline
\end{tabular}

Médias seguidas de mesma letra maiúscula na linha e minúscula na coluna, não diferem entre si pelo teste de Tukey $(\mathrm{P}<0,05)$.

TABELA4. Médias de plântulas fortes (\%) obtidas de sementes de cenoura, cv. Brasília, condicionadas em soluções aeradas de PEG 6000 e água destilada, por períodos de zero (testemunha), 12, 24 e 48 horas de embebição e submetidas à secagem $(\mathrm{CV}=36,86 \%)$

\begin{tabular}{clcc}
\hline \multirow{2}{*}{ Período (horas) } & \multirow{2}{*}{ Água destilada } & \multicolumn{2}{c}{$\left[\right.$ PEG 6000] $\left(\mathrm{g} \mathrm{L}^{-1}\right)$} \\
\cline { 3 - 4 } & & 161,30 & 240,97 \\
\hline zero & $2,5 \mathrm{Ac}$ & $2,5 \mathrm{Ab}$ & $2,5 \mathrm{Ab}$ \\
12 & $22,0 \mathrm{Ab}$ & $19,5 \mathrm{Aa}$ & $10,5 \mathrm{Aab}$ \\
24 & $30,0 \mathrm{Aab}$ & $31,0 \mathrm{Aa}$ & $22,5 \mathrm{Aa}$ \\
48 & $40,5 \mathrm{Aa}$ & $23,5 \mathrm{Ba}$ & $17,0 \mathrm{Bab}$ \\
\hline
\end{tabular}

Médias seguidas de mesma letra maiúscula na linha e minúscula na coluna, não diferem entre si pelo teste de Tukey $(\mathrm{P}<0,05)$. 
relação ao condicionamento em soluções de PEG e, nos demais tratamentos, não foram observadas diferenças significativas (Tabela 6). Este resultado reforça as evidencias de que períodos mais prolongados e potenciais osmóticos mais negativos podem prejudicar o crescimento normal das plântulas, como verificado por Trigo et al. (1999c).

A massa seca de plântulas após o condicionamento osmótico seguido de secagem não foi alterada em relação à testemunha (Tabela 7). Estes resultados diferem daqueles verificados por Trigo et al. (1999c), onde o condicionamento de sementes de cebola em soluções aeradas de PEG contribuíram significativamente para o aumento de massa seca da parte aérea e da raiz primária das plântulas.

Os valores obtidos de condutividade elétrica para as sementes sem condicionamento foram superiores aqueles obtidos após o condicionamento osmótico e secagem (Tabela 8 ). Esta diferença de valores reflete os danos provocados nas membranas celulares decorrentes da rápida absorção de água pelas células devido à diferença de potencial hídrico, que nas células de sementes secas encontra-se muito negativo. A absorção de água pela semente seca provoca a síntese de giberelinas, responsáveis pelo estímulo à produção de hidrolases. A clivagem das reservas, em metabólitos

TABELA5. Médias plântulas fracas (\%) de cenoura, cv. Brasília, condicionadas em soluções aeradas de PEG 6000 e água destilada, por períodos de zero (testemunha), 12, 24 e 48 horas de embebição e após secagem $(\mathrm{CV}=12,45 \%)$

\begin{tabular}{clcc}
\hline \multirow{2}{*}{ Período (horas) } & \multirow{2}{*}{ Água destilada } & \multicolumn{2}{c}{$[\mathrm{PEG} 6000]\left(\mathrm{g} . \mathrm{L}^{-1}\right)$} \\
\cline { 2 - 4 } & & 161,30 & 240,97 \\
\hline zero & $52,5 \mathrm{Aab}$ & $52,5 \mathrm{Aa}$ & $52,5 \mathrm{Aa}$ \\
12 & $51,0 \mathrm{Bab}$ & $49,0 \mathrm{Ba}$ & $62,5 \mathrm{Aa}$ \\
24 & $56,0 \mathrm{Aa}$ & $43,5 \mathrm{Ba}$ & $56,5 \mathrm{Aa}$ \\
48 & $40,5 \mathrm{Bb}$ & $54,5 \mathrm{Aa}$ & $65,5 \mathrm{Aa}$ \\
\hline
\end{tabular}

Médias seguidas de mesma letra maiúscula na linha e minúscula na coluna, não diferem entre si pelo teste de Tukey $(\mathrm{P}<0,05)$.

TABELA 6. Médias do comprimento $(\mathrm{cm})$ de plântulas obtidas de sementes de cenoura, cv. Brasília, condicionadas em soluções aeradas de PEG 6000 e água destilada, por períodos de zero (testemunha), 12, 24 e 48 horas de embebição e submetidas à secagem $(\mathrm{CV}=\mathbf{8 , 6 4 \%})$

\begin{tabular}{clrr}
\hline \multirow{2}{*}{ Período (horas) } & \multirow{2}{*}{ Água destilada } & \multicolumn{2}{c}{$\left[\right.$ PEG 6000] $\left(\mathrm{g} . \mathrm{L}^{-1}\right)$} \\
\cline { 3 - 4 } & & 161,30 & 240,97 \\
\hline Zero & $5,71 \mathrm{Aa}$ & $5,71 \mathrm{Aa}$ & $5,71 \mathrm{Aa}$ \\
12 & $5,63 \mathrm{Aa}$ & $5,39 \mathrm{Aa}$ & $5,48 \mathrm{Aa}$ \\
24 & $6,05 \mathrm{Aa}$ & $6,61 \mathrm{Aa}$ & $5,25 \mathrm{Aa}$ \\
48 & $5,97 \mathrm{Aa}$ & $5,05 \mathrm{Ba}$ & $5,01 \mathrm{Ba}$ \\
\hline
\end{tabular}

Médias seguidas de mesma letra maiúscula na linha e minúscula na coluna, não diferem entre si pelo teste de Tukey $(\mathrm{P}<0,05)$. secundários, por estas enzimas, torna o potencial hídrico ainda mais negativo, promovendo uma maior absorção de água e conseqüente aumento da pressão de turgescência da célula. $\mathrm{O}$ rápido aumento do potencial de pressão não permite a reorganização das microfibrilas de celulose da parede celular a tempo de evitar a ruptura e conseqüente extravasamento celular (Bewley e Black, 1994). Quando as sementes são condicionadas em soluções de PEG 6000 em potenciais hídricos negativos, o extravasamento das células é menor devido à absorção de água ser mais lenta. Isso permite a reorganização da parede celular, evitando a perda de solutos (Bradford, 1986). Neste caso as sementes passaram por processo prévio de embebição e solutos foram lixiviados para o meio de embebição (Tabela 9). Em sementes de milho doce, após o osmo e matricondicionamento, Sung e Chang (1993) também observaram diminuição da condutividade elétrica nestas sementes. Resultados semelhantes foram obtidos por Rudrapal e Nakamura (1988) que observaram menores leituras de condutividade elétrica em sementes de berinjela e rabanete condicionadas indicando redução de extravasamento celular. Considerando inicialmente o efeito do período, os resultados mostraram que a partir de 12 horas de condicionamento não ocorreu mais lixiviação de solutos para a solução (Tabelas 8 e 9).

TABELA 7. Médias do peso de massa seca (g) de plântulas de cenoura, cv. Brasília, condicionadas em soluções aeradas de PEG 6000 e água destilada, por períodos de zero (testemunha), 12, 24 e 48 horas de embebição e submetidas à secagem $(\mathrm{CV}=17,54 \%)$

\begin{tabular}{clrr}
\hline \multirow{2}{*}{ Período (horas) } & \multirow{2}{*}{ Água destilada } & \multicolumn{2}{c}{$\left[\right.$ PEG 6000] $\left(\mathrm{g} . \mathrm{L}^{-1}\right)$} \\
\hline zero & $0,203 \mathrm{Aa}$ & 161,30 & \multicolumn{1}{c}{240,97} \\
12 & $0,227 \mathrm{Aa}$ & $0,203 \mathrm{Aa}$ & $0,203 \mathrm{Aa}$ \\
24 & $0,195 \mathrm{Aa}$ & $0,227 \mathrm{Aa}$ & $0,225 \mathrm{Aa}$ \\
48 & $0,210 \mathrm{Aa}$ & $0,182 \mathrm{Aa}$ & $0,192 \mathrm{Aa}$ \\
\hline
\end{tabular}

Médias seguidas de mesma letra maiúscula na linha e minúscula na coluna, não diferem entre si pelo teste de Tukey $(\mathrm{P}<0,05)$.

TABELA 8. Médias de condutividade elétrica $\left(\mu \mathrm{S} . \mathrm{cm}^{-1} \cdot \mathrm{g}^{-1}\right)$ de sementes de cenoura condicionadas em soluções aeradas de PEG 6000 e água destilada, por períodos de zero (testemunha), 12, 24 e 48 horas de embebição e submetidas à secagem $(\mathrm{CV}=6,68 \%)$

\begin{tabular}{cccc}
\hline \multirow{2}{*}{ Período (horas) } & \multirow{2}{*}{ Água destilada } & \multicolumn{2}{c}{$\left[\right.$ PEG 6000] $\left(\mathrm{g} . \mathrm{L}^{-1}\right)$} \\
\hline & & 161,30 & 240,97 \\
\hline zero & $779,52 \mathrm{Aa}$ & $779,52 \mathrm{Aa}$ & $779,52 \mathrm{Aa}$ \\
12 & $55,77 \mathrm{Ab}$ & $64,82 \mathrm{Ab}$ & $77,90 \mathrm{Ab}$ \\
24 & $44,95 \mathrm{Bb}$ & $57,22 \mathrm{ABb}$ & $73,35 \mathrm{Ab}$ \\
48 & $69,97 \mathrm{Ab}$ & $70,00 \mathrm{Ab}$ & $74,60 \mathrm{Ab}$ \\
\hline
\end{tabular}

Médias seguidas de mesma letra maiúscula na linha e minúscula na coluna, não diferem entre si pelo teste de Tukey $(\mathrm{P}<0,05)$. 
TABELA 9. Médias de condutividade elétrica das soluções de

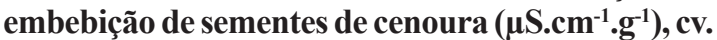
Brasília, após o condicionamento osmótico em PEG 6000 e água destilada, por períodos de 12, 24 e 48 horas de embebição. $(\mathrm{CV}=\mathbf{1 0 , 7 \%})$

\begin{tabular}{clcc}
\hline \multirow{2}{*}{ Período (horas) } & \multirow{2}{*}{ Água destilada } & \multicolumn{2}{c}{$\left[\right.$ PEG 6000] $\left(\right.$ g.L $\left.^{-1}\right)$} \\
\cline { 3 - 4 } & & 161,30 & 240,97 \\
\hline 12 & $1887 \mathrm{Aa}$ & $1391 \mathrm{Ba}$ & $1137 \mathrm{Ba}$ \\
24 & $2030 \mathrm{Aa}$ & $1397 \mathrm{Ba}$ & $1193 \mathrm{Ba}$ \\
48 & $1974 \mathrm{Aa}$ & $1395 \mathrm{Ba}$ & $1121 \mathrm{Ba}$ \\
\hline
\end{tabular}

Médias seguidas de mesma letra maiúscula na linha e minúscula na coluna, não diferem entre si pelo teste de Tukey $(\mathrm{P}<0,05)$.

Comparando-se os valores de condutividade elétrica após o condicionamento e secagem das sementes (Tabela 8), com aqueles obtidos das soluções usadas para a embebição (Tabela 9), observou-se uma perda de solutos das sementes para as soluções condicionantes, corroborando com as suposições de Bray (1995) e Roveri-José et al. (2000), em que a lixiviação de solutos durante o condicionamento osmótico pode ter contribuído para a redução dos valores de condutividade elétrica. Esta perda foi maior para o condicionamento em água e menor para o tratamento com polietileno glicol na concentração de $240,97 \mathrm{~g} . \mathrm{L}^{-1}$, devido, provavelmente, ao menor dano de embebição e lixiviação de solutos quando as sementes estavam em contato com as soluções osmóticas em potenciais hídricos negativos. Entretanto, estas perdas de solutos para o meio de embebição, principalmente quando no condicionamento em água destilada, não afetou as atividades fisiológicas na germinação e no vigor destas sementes.

Embora os resultados obtidos por outros trabalhos (Biniek e Babik, 1993; Peluzio et al., 1999) evidenciem o aumento do vigor das sementes osmocondicionadas de cenoura, neste trabalho o condicionamento em água destilada por período de até 48 horas, no sistema de embebição com suprimento de aeração, mostrou-se promissor como alternativa ao condicionamento fisiológico das sementes. No entanto, há necessidade de se realizar outros trabalhos isolando os efeitos da secagem, do armazenamento, assim como, o desenvolvimento posterior das plântulas em condições de campo e a produtividade final.

\section{CONCLUSÕES}

A secagem das sementes de cenoura após o condicionamento osmótico não afetou a sua germinação.

O condicionamento das sementes em água destilada, por até 48 horas em sistema aerado seguido de secagem, contribuiu para aumentar o vigor das sementes de cenoura.

\section{REFERÊNCIAS}

ARAGÃO, C.; MORAIS, O.M.; VALLE LIMA, E.; LOMOS, L.B.; CARIANI, C.; NAKAGAWA, J. Efeito da hidratação seguida de secagem na qualidade fisiológica de sementes de feijão. Revista Brasileira de Sementes, Brasília, v. 21, n. 2, p. 180-186, 1999.

BEWLEY,J.D.; BLACK, M. Seeds: physiology of development and germination.2 ed. New York: Plenum Press, 1994. p. 293-343.

BINIEK, A.; BABIK, I. The influence of osmoconditioning in polyethylene glicol (PEG 6000) on the germination and emergence of carrot and parsley seeds. Acta Horticulturae, Wageningen, v.371, p. 77-81,1993

BRADFORD, K.J. Manipulation of seed water relations via osmotic priming to improve germination under stress conditions. HortScience, Alexandria, v. 21, p. 1105-1112, 1986.

BRASIL. Ministério da Agricultura e da Reforma Agrária. Regras para análise de sementes. Brasília: SNDA/DNDV/CLAV, 1992. $365 \mathrm{p}$.

BRAY, C.M. Biochemical processes during the osmopriming of seeds. In: KIGEL, J. ; GALILI, G. (Ed) Seed development and germination. New York: Marcel Dekker 1995. p.767-789.

CARNEIRO, J.W.P.; BRACCINI, A.L.; GUEDES, T.A.; AMARAL, D. Influência do estresse hídrico, térmico e do condicionamento osmótico no desempenho germinativo de sementes de cenoura (Daucus carota L.). Revista Brasileira de Sementes, Brasília, v.21, n.2, p.208-216, 1999.

CARVALHO, L.F.; FILHO, S.M.; ROSSETTI,A.G.; TEÓFILO, E.M. Condicionamento osmótico em sementes de sorgo. Revista Brasileira de Sementes, Brasília, v.22, n.1, p.185-192, 2000.

CUSTÓDIO, C.C.; MACHADO NETTO, N.B; MASSAKITTO, H.; VIVAN, M.R. Efeito da submersão em água de sementes de feijão na germinação e no vigor: Revista Brasileira de Sementes, Londrina,v. 24, n. 2, p. 49-54, 2002.

EGLI. D.B.; TEKRONY, D.M. Species differences in seed water status during seed maturations and germination. Seed Science Research, Wallingford, v.7, p. 3-11, 1997.

FESSEL, S.A.; VIEIRA, R.D.; RODRIGUES, T.J.D. Germinação de sementes de alface submetidas a condicionamento osmótico durante o armazenamento. Scientia Agricola, Piracicaba, v.59, n.1, p.73-77, 2002.

HEYDECKER, W.; HIGGINS, J.; TURNER, I.J. Invigoration of seeds? Seed Science and Technology, Zürich,v.3, n. 1, p.881-888, 1975.

LOPES, H. M.; ROSSETTO, C. A. V. ; CARNEIRO, V. Embebição de sementes de cenoura (Daucus carota L.) em diferentes potenciais osmóticos por dois métodos. Revista Brasileira de Sementes, Brasília, v.22, n.1, p.81-87, 2000.

McDONALD, M.B. Seed quality assessment. Seed Science Research, Wallingford, v.8, p.265-275, 1998.

MICHEL, B.E.; KAUFMANN, M.R. The osmotic potencial of polyethylene glycol 6000. Plant Physiollogy, Rockville, v.51, n.6, p.914-916, 1973 .

NAKAGAWA, J. Testes de vigor baseados do desempenho das 
plântulas. In: KRZYZANOWSKI, F.C.; VIEIRA, R.D.; FRANCCA NETO, J.B.(Ed.). Vigor de sementes: conceitos e testes. Londrina: ABRATES 1999. p. 2-24.

NASCIMENTO, W.M. Condicionamento osmótico de sementes de hortaliças: potencialidades e implicações. Horticultura Brasileira, Brasília, v.16, n.2, p.106-109, 1998.

NUNES, U.R.; SANTOS, M.R.; ALVARENGA, E.M.; DIAS, D.C.F.S. Efeito do condicionamento osmótico e do tratamento com fungicida na qualidade fisiológica e sanitária de sementes de cebola (Allium cepa L.). Revista Brasileira de Sementes, Brasília, v.22, n.1, p.239-246, 2000.

PELUZIO, L.E.; SILVA, R.F.; REIS, M.S.; CECON, P.R.; DIAS, D.C.F.S.; PELUZIO, J.B.E. Efeito do condicionamento osmótico na embebição e na germinação de sementes de cenoura (Daucus carota L.). Revista Brasileira de Sementes, Brasília, v.21, n.2, p.161-169, 1999.

POWELL, A.A. Seleção e envigoramento como técnicas para o aprimoramento do desempenho de sementes. Scientia Agricola, Piracicaba, v. 55, p.126-133, 1998.

ROVIERI-JOSÉ, S.C.B.; VIEIRA, M.G.G.C.; GUIMARÃES, R.M. Efeito da temperatura e do período de condicionamento osmótico na germinação e no vigor de sementes de pimentão. Revista Brasileira de Sementes, Brasília, v.22, n.2, p.176-184, 2000.

RUDRAPAL,D. ; NAKAMURA, S.The effect of hydrationdehydration pretreatments on eggplant and radish seed viability and vigour. Seed Science and Technology, Zürich, v.16, p. 123130. 1988

SUNG, F.J.M.; CHANG, Y.H. Biochemical activities associated with priming of sweet corn seeds to improve vigor. Seed Science and Technology, Zürich, v.21, p. 97-105, 1993.

SANTOS, C.M.R.; MENEZES, N.L. Tratamentos pré-germinativos em sementes de alface. Revista Brasileira de Sementes, Brasília, v.22, n. 1, p.153-158, 2000.

TAYLOR, A.G.; ALLEN, P.S.; BENNETT, K.J. Seed enhancements. Seed Science Research, Wallingford, v.8, p.245-256, 1998.

TRIGO, M.F.O.O.; NEDEL, J.L.; TRIGO, L.F.N. Condicionamento osmótico em sementes de cebola: I. efeitos sobre a germinação. Scientia Agricola, Piracicaba, v.56, n. 4, p.1059-1067, 1999 a.

TRIGO, M.F.O.O.; NEDEL, J.L.; GARCIA, A.; TRIGO, L.F.N. Efeitos do condicionamento osmótico com soluções aeradas de nitrato de potássio no desempenho de sementes de cebola. Revista Brasileira de Sementes, Brasília, v.21, n.1, p.139-144, 1999b.

TRIGO, M.F.O.O.; NEDEL, J.L.; LOPES, N.L.; TRIGO, L.F.N. Osmocondicionamento de sementes de cebola (Allium cepa L.) com soluções aeradas de polietileno glicol. Revista Brasileira de Sementes, Brasília, v.21, n.1, p.145-150, 1999c.

VIEIRA, R.D.; KRZYZANOWSKI, F.C. Teste de condutividade elétrica. In: KRZYZANOWSKI, F.C.; VIEIRA, R. D.; FRANÇA NETO, J.B. Vigor de Sementes: conceitos e testes. Londrina: ABRATES, 1999.p. 4.1 -4.26,

VILLELA, F.A.; MARCOS FILHO, J.; NOVEMBRE, A.D.L.C. Estado energético da água na semente de milho no processo de germinação. Revista Brasileira de Sementes, Londrina, v. 25, n. 1, p. 25-100, 2003. 